\title{
Migraine and cognitive decline among women: prospective cohort study
}

\author{
(c) $(1) \circledast$ OPEN ACCESS
}

\author{
Pamela M Rist fellow ${ }^{12}$, Jae H Kang assistant professor ${ }^{3}$, Julie E Buring professor ${ }^{12}$, M Maria \\ Glymour assistant professor ${ }^{4}$, Fran Grodstein associate professor ${ }^{23}$, Tobias Kurth director of \\ research $^{1256}$
}

${ }^{1}$ Division of Preventive Medicine, Department of Medicine, Brigham and Women's Hospital, Harvard Medical School, Boston, MA; ${ }^{2}$ Department of Epidemiology, Harvard School of Public Health, Boston, MA; ${ }^{3}$ Channing Laboratory, Department of Medicine, Brigham and Women's Hospital; ${ }^{4}$ Department of Society, Human Development, and Health, Harvard School of Public Health; ${ }^{5}$ INSERM Unit 708-Neuroepidemiology, Bordeaux, France; ${ }^{6}$ University of Bordeaux, Bordeaux, France

\begin{abstract}
Objective To evaluate the association between migraine and cognitive decline among women.

Design Prospective cohort study.

Setting Women's Health Study, United States.

Participants 6349 women aged 65 or older enrolled in the Women's Health Study who provided information about migraine status at baseline and participated in cognitive testing during follow-up. Participants were classified into four groups: no history of migraine, migraine with aura, migraine without aura, and past history of migraine (reports of migraine history but no migraine in the year prior to baseline).
\end{abstract}

Main outcome measures Cognitive testing was carried out at two year intervals up to three times using the telephone interview for cognitive status, immediate and delayed recall trials of the east Boston memory test, delayed recall trial of the telephone interview for cognitive status 10 word list, and a category fluency test. All tests were combined into a global cognitive score, and tests assessing verbal memory were combined to create a verbal memory score.

Results Of the 6349 women, $853(13.4 \%)$ reported any migraine; of these, 195 (22.9\%) reported migraine with aura, $248(29.1 \%)$ migraine without aura, and $410(48.1 \%)$ a past history of migraine. Compared with women with no history of migraine, those who experienced migraine with or without aura or had a past history of migraine did not have significantly different rates of cognitive decline in any of the cognitive scores: values for the rate of change of the global cognitive score between baseline and the last observation ranged from -0.01 (SE 0.04) for past history of migraine to 0.08 (SE 0.04) for migraine with aura when compared with women without any history of migraine. Women who experienced migraine were also not at increased risk of substantial cognitive decline (worst $10 \%$ of the distribution of decline). When compared with women without a history of migraine, the relative risks for the global score ranged from 0.77 (95\% confidence interval 0.46 to 1.28) for women with migraine without aura to 1.17 (0.84 to 1.63) for women with a past history of migraine.

Conclusion In this prospective cohort of women, migraine status was not associated with faster rates of cognitive decline.

\section{Introduction}

Migraine is a chronic-intermittent primary headache disorder that affects about $20 \%$ of the female population. ${ }^{1}$ Up to one third of those with migraine experience aura (that is, transient neurology symptoms mainly of the visual field) before or during a migraine attack. Besides the headache, migraine is believed to usually be a benign condition. However, previous studies have linked migraine, especially migraine with aura, to an increased risk of ischaemic stroke. ${ }^{2}$ In addition to increasing the risk of stroke, migraine has also been associated with an increased prevalence of clinically silent brain lesions. ${ }^{3-5}$ In the general population, silent brain lesions have been shown to be a risk factor for dementia and cognitive decline, ${ }^{6}$ leading to speculation that migraine may be a progressive brain disorder. ${ }^{7}$ Determining if there is an association between migraine and cognitive decline among women is important because women are more likely than men to experience migraines ${ }^{1}$ and also have a higher prevalence of dementia. ${ }^{8}$ If an association between migraine and cognitive decline does exist, preventing the onset of migraines may be one way to slow the progression of cognitive decline. Additionally, interventions aimed at preserving cognitive function could be targeted to women who experience migraine.

Although several cross sectional studies ${ }^{9-19}$ and a few prospective studie ${ }^{20-22}$ have examined the association between migraine and cognitive decline, many were small or were unable to stratify 
the association between migraine and cognitive decline by aura status. Using data from the Women's Health Study, we examined the association between migraine subtypes and cognitive decline during four years of follow-up.

\section{Methods}

The Women's Health Study was a randomised, placebo controlled clinical trial designed to test the effects of low dose aspirin and vitamin $\mathrm{E}$ in the primary prevention of cardiovascular disease and cancer. The design and results of the study have been reported previously. ${ }^{23-25}$ Briefly, at baseline (1992-95), 39876 US female health professionals age 45 or older without a history of cardiovascular disease, cancer, or other major illnesses were enrolled. The clinical trial ended in March 2004, and the women are currently being followed in an observational study.

In 1998, a cognitive subcohort of women participating in the Women's Health Study was started. ${ }^{26}{ }^{27}$ Women were eligible to participate if they were aged 65 or older. Of the 7175 women eligible to participate, 6377 completed the initial cognitive assessment. Two additional follow-up assessments were done, each about two years apart. Of those who completed the initial assessment, 5845 (91.7\%) completed at least one follow-up assessment and 5073 (79.5\%) completed all assessments. About $8 \%$ of participants did not complete any follow-up assessments owing to death $(2 \%)$, being unreachable $(1 \%)$, or refusal $(5 \%)$.

\section{Assessment of migraine}

On the baseline questionnaire we asked the women "Have you ever had migraine headaches?" and "In the past year, have you had migraine headaches?" We also asked the women who reported experiencing migraine headaches within the past year about the characteristics of their attacks, including the presence of aura or any indication that a migraine was coming. Using the women's responses to these questions, we divided them into four categories: no migraine history, migraine with aura (women who indicated experiencing migraine within the year before baseline and who reported the presence of aura or any indication that a migraine was coming), migraine without aura, and a past history of migraine (women who reported ever having migraine headache but not experiencing migraine headache within the year before baseline). Previous validation studies in the Women's Health Study have shown good agreement between self reported migraine and the International Classification of Headache Disorders I and II. ${ }^{28}{ }^{29}$ For this analysis we excluded the 28 women who did not provide information on migraine status at baseline. The figure $\Downarrow$ shows the number of women included and excluded at each stage of the design.

\section{Assessment of outcomes}

Interviewers blinded to the participant's migraine status administered the telephone cognitive assessment. The assessment was composed of five separate tests: telephone interview for cognitive status, immediate and delayed recall trials of the east Boston memory test, delayed recall trial of the telephone interview for cognitive status 10 word list, and a category fluency task. The telephone interview for cognitive status assesses global cognitive function and is a telephone adaptation of the mini-mental state examination. ${ }^{30}$ Scores range from 0 to 41 points, and the test is shown to have high reliability and validity for measuring cognitive function. ${ }^{31}$ The east Boston memory test assesses verbal memory with scores ranging from 0 to 12 points. ${ }^{32}$ The delayed recall of the telephone interview for cognitive status 10 word list also assesses verbal memory.
The category fluency test assesses language and executive functioning ${ }^{26}{ }^{33}$ by asking women to name as many animals as possible in one minute. The validity of the telephone assessment compared with face to face interviews has been shown in previous studies ( $\mathrm{r}=0.81$ comparing our brief telephone administered cognitive assessment with face to face interviews composed of 21 tests). ${ }^{26} 34$

To create a global cognitive score we averaged $\mathrm{z}$ scores for performance on each of the five tests. For the $0.4 \%$ of participants who did not complete all five tests we used the mean of the $\mathrm{z}$ scores of the completed tests. We created a verbal memory composite score by averaging the $\mathrm{z}$ scores of the immediate and delayed recalls of both the east Boston memory test and the telephone interview for cognitive status 10 word list. Both of these composite scores have been used in previous studies in the Women's Health Study. ${ }^{26} 2733$ Finally, we also examined separately scores on the telephone interview for cognitive status as an additional measure of global cognition and scores on the category fluency task as executive function is particularly affected by clinical or subclinical stroke.

\section{Statistical analysis}

We calculated means for continuous baseline characteristics and frequencies for categorical baseline characteristics. At each cognitive assessment we used repeated measures analyses to examine mean performance. We adjusted for several potential confounders, as measured at baseline: age (continuous), smoking status (never, former, current), alcohol consumption ( $\leq 3$ drinks per month, 1-6 drinks per week, $\geq 1$ drinks per day), body mass index $\left(<25,25-29.9, \geq 30 \mathrm{~kg} / \mathrm{m}^{2}\right)$, educational attainment (less than a bachelors degrees versus bachelors degree or above), use of postmenopausal hormones (never, current, or past), history of high cholesterol levels (yes or no), treatment for high cholesterol levels (yes or no), history of hypertension (yes or no), treatment for hypertension (yes or no), diabetes (yes or no), and history of oral contraceptive use (yes or no).

To examine change in cognitive functioning over time we used general linear models of response profiles. Similar to previous studies done using data from the Women's Health Study, ${ }^{26} 2733$ we modelled time nominally rather than linearly (since there was not a linear relation between time and cognitive performance) and modelled the effect of migraine status over time (the joint effects of migraine and time) by using interaction terms between migraine status and time. All models were fitted using maximum likelihood and accounted for the longitudinal correlation within participants by using an unstructured covariance matrix. We carried out age and multivariable adjusted analyses. The multivariable analysis adjusted for the same potential confounders as the repeated measures analysis of means with the exception of excluding treatment for high cholesterol levels for the global score and category fluency outcomes due to problems with model convergence. We also tested for effect modification by age (dichotomised at the median age of 75 years), history of hypertension, cardiovascular disease (all incident occurrences from baseline to the end of the cognitive substudy), baseline score for the global score, verbal score, telephone interview for cognitive status, and category fluency score (dichotomised at the median), perceived change in memory (worse versus no change or improvement), and educational attainment. The testing was done by including a three way interaction term for each variable with migraine status and time in separate age adjusted models.

We assigned women with missing information on body mass index $(n=149)$ to a separate category. For other covariates, the 
number of women with missing information was small $(<100$ for each variable), so we assigned them to the never/rarely or no use categories or, in the case of education, we used information on years of education to impute their highest educational attainment.

We carried out additional analyses using logistic regression to determine if migraine increased the risk of "substantial" cognitive decline. Substantial cognitive decline was defined as the worst $10 \%$ of the distribution of decline from the initial to the final cognitive assessment of the whole study cohort. We adjusted for all variables included in our previous analyses of mean scores and also adjusted for the time between entry into the Women's Health Study and third cognitive assessments.

All models were fit using SAS 9.1. All probability values were two tailed, and we considered $\mathrm{P}<0.05$ to be statistically significant.

\section{Results}

Of the 6349 women, 853 (13.4\%) reported any migraine; of these, $195(22.9 \%)$ reported migraine with aura, $248(29.1 \%)$ migraine without aura, and $410(48.1 \%)$ a past history of migraine. Table $1 \Downarrow$ shows the baseline characteristics of the participating women. Women who experienced migraine with aura were less likely to consume alcohol than women in the other migraine categories. Women who reported a past history of migraine had less education than women without any history of migraine, migraine with aura, or migraine without aura. Women with no history of migraine were more likely to have diabetes. Women with migraine without aura were the least likely to exercise.

The mean follow-up time for the cognitive substudy was 3.4 years. Table $2 \Downarrow$ shows the average test scores at each cognitive assessment by migraine status adjusted for potential confounders. The global scores, verbal scores, or telephone interview for cognitive status scores did not differ significantly among the migraine categories. For the category fluency test, the scores differed significantly among the migraine groups at the second and third cognitive testing. Overall, cognitive performance seemed to be similar or even slightly better for women in the migraine groups than for women with no history of migraine.

Table $3 \Downarrow$ presents the results from age and multivariable adjusted longitudinal analyses. All of the interaction terms between migraine categories and time were close to the null and non-significant, providing no evidence of differences in rates of cognitive decline for those with no history of migraine compared with women who experienced migraine with or without aura or had a past history of migraine.

The risk of substantial cognitive decline in women who experienced migraine with or without aura or had a past history of migraine was not increased (table $4 \Downarrow$ ) compared with those with no history of migraine. In secondary analyses, we found no evidence of significant effect modification by history of hypertension, baseline score, perceived change in memory, or educational attainment. Statistically significant effect modification by age (less than or higher than the median of 75 years) was observed for the telephone interview for cognitive status $(\mathrm{P}=0.02)$. This result seemed to be driven by a greater rate of cognitive decline at the third time point among those with a past history of migraine who were older than the median age ( $\beta$ coefficient -0.85 ) compared with those who were younger than the median age ( $\beta$ coefficient 0.07 ). No statistically significant effect modification by median age was observed for the other cognitive outcomes. Statistically significant effect modification by cardiovascular disease was observed on the category fluency test $(\mathrm{P}=0.01)$. Among women who experienced migraine with aura, those who also experienced a cardiovascular event had greater rates of decline ( $\beta$ coefficient -2.76 at the second time point and $\beta$ coefficient -2.43 at the third time point) than those who did not experience a cardiovascular event $(\beta$ coefficient -0.50 at the second time point and $\beta$ coefficient 0.70 at the third time point). No statistically significant effect modification by cardiovascular event was observed for the other cognitive outcomes.

\section{Discussion}

Results from this large, prospective cohort study among women provide no evidence that migraine is associated with greater rates of cognitive decline when compared with women without a history of migraine. This result did not differ according to migraine aura status or past history of migraine. We also did not observe meaningful effect modification of this lack of association for most of our migraine groups. We did observe some effect modification by age for those with a past history of migraine, suggesting that older women had faster rates of decline on the telephone interview for cognitive status than younger women. Additionally, among women with migraine with aura, those who experienced a cardiovascular event had faster rates of decline on the category fluency test than those without a cardiovascular event.

\section{Comparisons with other studies}

Cross sectional studies have shown mixed results on the association between migraine status and lower cognitive functioning. Some studies have shown no differences among those with and without migraine, ${ }^{9-14}$ whereas others have shown evidence of worse cognitive functioning among those who experience migraine. ${ }^{15-19}$ However, owing to their cross sectional nature, none of these studies could examine the association between migraine and cognitive decline, a more meaningful outcome than cognition at any single time point.

The prospective studies on the association between migraine and cognitive decline among adults have not found greater rates of cognitive decline among people with migraine compared with people without migraine. ${ }^{20-22}$ The Baltimore cohort of the National Institute of Health Mental Health Epidemiology Catchment Area study found that although adults with migraine overall and those with migraine with aura who were aged 50 or older at baseline showed lower baseline scores on tests of delayed and immediate recall, they actually showed less decline in those tests over time compared with people aged 50 or older at baseline who did not have migraines. Rates of decline did not differ between people aged less than 50 at baseline with migraine and those without. ${ }^{21}$ The Maastricht Ageing Study did not find differences between people with and without migraine in decline on the mini-mental state examination, immediate and delayed recall of tests with 15 word lists, or other tests for simple and complex speed. ${ }^{20}$ Finally, the Epidemiology of Vascular Ageing Study found no evidence of greater cognitive decline among people who experienced migraine on any of a wide variety of cognitive tests. For the Wechsler adult intelligence scale-revised, there was evidence that people who experienced migraine declined less over time than those with no history of severe headache. There was also little evidence that the presence of white matter hyperintensities or brain infarction modified the association between migraine and cognitive decline. ${ }^{22}$

In the present study we also found little evidence that cognitive function among those who experienced migraine declined more 
than those without a history of migraine. Since this study was much larger than previous studies, we were able to examine the impact of migraine with aura, migraine without aura, and past history of migraine. Examining the association between migraine and cognitive decline by aura status is important because migraine with aura has been linked to more deleterious effects on the brain, particularly ischaemic vascular changes. ${ }^{4}$ Additionally, we were able to carry out other subgroup analyses by age or the presence of cardiovascular disease, which could not be done in previous studies.

\section{Strengths and limitations of the study}

The strengths of this study include its large prospective design, standardised assessment of migraine status, information on migraine with and without aura, and the availability of validated cognitive function measures ${ }^{26}{ }^{34}$ at multiple time points, which allowed us to examine change in cognitive function over time.

Several limitations should be considered when interpreting our results. Our cohort was composed of women aged 65 and older, mostly white, female health professionals, which might limit the ability to generalise our results to other cohorts. However, we do not believe that the biological mechanisms linking migraine with cognitive decline would be different in our cohort compared with other populations. Since migraine was self reported, women may incorrectly report their migraine status. However, all participants were health professionals who are known to report health information accurately. Furthermore, validation studies have shown good agreement between self reported migraine and the International Classification of Headache Disorders I and II. ${ }^{28}{ }^{29}$ Although our study was not able to examine the impact of migraine on cognitive decline among men, potential effects of migraine on subsequent conditions, such as cognitive decline, are of particular interest in women because of the longer life expectancy among women.

Overall we did not observe a large amount of cognitive decline among our participants, possibly because of the age of the participants and the short follow-up period. Additionally, although the telephone interview for cognitive status does not seem to show a ceiling effect as strong as that seen for the mini-mental state examination, ${ }^{35}$ it is possible that the women in our cohort may not have been declining enough for our "global score" to detect changes in cognitive status. However, other studies using this cohort have detected risk factors for cognitive decline, such as type 2 diabetes, longer duration of diabetes, educational status, and income, ${ }^{33}{ }^{36}$ which suggests that our study period was long enough to observe a meaningful cognitive decline. Given that the Baltimore Epidemiology Catchment Area Study had a much longer period of follow-up than our study (1993 to 2005) and also did not find evidence of worse decline among people who experience migraine further helps to ameliorate concerns that the women in our study may not have been followed for long enough to detect decline. Cognitive assessment was done several years after the start of the trial, so there could be possible bias due to loss to follow-up if women who experienced migraine were more likely to be lost to follow-up before the start of cognitive testing and had lower cognitive scores than women remaining in the cohort. However, only a small percentage of women $(1.5 \%)$ were lost to follow-up between baseline and cognitive assessment ${ }^{27}$ so any bias would be relatively small. We did have some loss to follow-up over the course of our study, but the percentage of women lost to follow-up in the migraine categories was similar to that among the women with no history of migraine. Finally, although this study is larger than many previous studies, we may not have had enough participants in our migraine categories to detect small differences in cognitive decline among our groups.

\section{Clinical implications}

Results of this study do not suggest that women with migraine with or without aura or with a past history of migraine have an increased risk of cognitive decline. Based on the results from this study and from previous studies using a wide variety of cognitive tests and various approaches to assessing migraine status, migraine does not seem to lead to functional impairments of the brain. Based on these results, patients with migraine and their treating doctors should be reassured that migraine may not have long term consequences on cognitive function. We did observe greater rates of cognitive decline in the subgroup of women who experience migraine with aura and had a history of cardiovascular disease compared with women who experience migraine with aura and did not have history of cardiovascular disease. However, because of the multiple subgroup analyses, this result should be interpreted with caution and further research is warranted to determine whether the interplay of migraine and cardiovascular disease leads to faster cognitive decline, and whether preventive strategies can be applied.

\section{Unanswered questions and future research}

Migraine is a complex disease and has been linked with various comorbidities, such as stroke and other vascular disease events. However, the mechanisms underlying these associations are not fully understood. Evaluating the interrelations between migraine and other diseases remains an important research target to establish strategies to positively influence the course of disease and to optimise treatment strategies.

Contributors: PMR designed the study and analysed and interpreted the data. JHK analysed the data. JEB designed the study, interpreted the data, and obtained funding. MMG designed the study and interpreted the data. FG conceived and designed the study, analysed and interpreted the data, obtained funding, and supervised the study. TK conceived and designed the study, analysed and interpreted the data, obtained funding, and supervised the study. All authors critically revised the manuscript for important intellectual content. FG and TK contributed equally to the study. The sponsor of the study had no role in the study design, data collection, data analysis, data interpretation, writing of the report, or in the decision to submit the paper. All authors had full access to all of the data in the study and can take responsibility for the integrity of the data and accuracy of the data analysis. PMR and TK act as guarantors for this study.

Funding: The Women's Health Study is supported by grants from the National Heart, Lung, and Blood Institute (HL-043851, HL-080467, HL-099355) and the National Cancer Institute (CA-47988). The cognitive substudy of the Women's Health Study was supported by a grant from the National Institute of Aging (AG-15933). PMR was supported by a training grant from the National Institute of Aging (AG-00158). TK is supported in part by a Chair of Excellence grant of the French National Research Agency (Agence Nationale de la Recherche, R09177DD).

Competing interests: All authors have completed the ICMJE uniform disclosure form at www.icmje.org/coi_disclosure.pdf (available on request from the corresponding author) and declare: that this study has been funded by the US National Institutes of Health; PMR was funded by a training grant from the US National Institute of Aging and has received funding from the Rose Traveling Fellowship Program in Chronic Disease Epidemiology and Biostatistics from the Harvard School of Public Health and received a travel grant from the Department of Epidemiology at the Harvard School of Public Health; JHK has received investigator initiated funding from the US National Institutes of Health, 


\section{What is already known on this topic}

Several cross sectional studies and a few prospective cohort studies have examined the association between migraine and cognition Many of these studies were, however, small or unable to stratify the association by migraine aura status

\section{What this study adds}

Results from this large, prospective cohort study among women provide no evidence that women who experience migraine with aura or migraine without aura have greater rates of cognitive decline than women without a history of migraine

American Heart Association, and Wyeth (now Pfizer) Pharmaceuticals; JEB has received investigator initiated research funding and support from the US National Institutes of Health and Dow Corning, and research support for pills or packaging from Bayer HealthCare and the Natural Source Vitamin E Association; MMG receives or has received research support from the US National Institutes of Health, the Robert Wood Johnson Foundation Health and Society Scholars Program, the MacArthur Foundation Network on Socioeconomic Status and Health, the Milton Fund for Harvard University Junior Faculty, and the American Heart Association; FG has received investigator initiated funding from the US National Institutes of Health and the California Strawberry Council; TK has received investigator initiated research funding from the French National Research Agency, the US National Institutes of Health, Merck, the Migraine Research Foundation, and the Parkinson's Disease Foundation, and honorariums from the $B M J$ for editorial services, Allergan, the American Academy of Neurology, Merck for educational lectures, and MAP Pharmaceutical for contributing to a scientific advisory panel; and no other relationships or activities that could appear to have influenced the submitted work.

Ethical approval: This study was approved by the institutional review board of Brigham and Women's Hospital, Boston, MA (protocol No 1999P002903). All participants provided written informed consent to participate in the Women's Health Study.

Data sharing: No additional data available.

1 Bigal ME, Lipton RB. The epidemiology, burden, and comorbidities of migraine. Neurol Clin 2009;27:321-34.

2 Schurks M, Rist PM, Bigal ME, Buring JE, Lipton RB, Kurth T. Migraine and cardiovascular disease: systematic review and meta-analysis. BMJ 2009;339:b3914.

3 Kruit MC, van Buchem MA, Hofman PA, Bakkers JT, Terwindt GM, Ferrari MD, et al. Migraine as a risk factor for subclinical brain lesions. JAMA 2004;291:427-34

4 Kurth T, Mohamed S, Maillard P, Zhu YC, Chabriat H, Mazoyer B, et al. Headache, migraine, and structural brain lesions and function: the population-based Epidemiology of Vascular Ageing-MRI study. BMJ 2011;342:c7357.

5 Scher Al, Gudmundsson LS, Sigurdsson S, Ghambaryan A, Aspelund T, Eiriksdottir G, et al. Migraine headache in middle age and late-life brain infarcts. JAMA 2009;301:2563-70.

6 Vermeer SE, Prins ND, den Heijer T, Hofman A, Koudstaal PJ, Breteler MM. Silent brain infarcts and the risk of dementia and cognitive decline. N Engl J Med 2003;348:1215-22.

7 Lipton RB, Pan J. Is migraine a progressive brain disease? JAMA 2004;291:493-4.

8 Ott A, Breteler MM, van Harskamp F, Stijnen T, Hofman A. Incidence and risk of dementia. The Rotterdam study. Am J Epidemiol 1998;147:574-80.

9 Gaist D, Pedersen L, Madsen C, Tsiropoulos I, Bak S, Sindrup S, et al. Long-term effects of migraine on cognitive function: a population-based study of Danish twins. Neurology 2005;64:600-7.

10 Haverkamp F, Honscheid A, Muller-Sinik K. Cognitive development in children with migraine and their healthy unaffected siblings. Headache 2002;42:776-9.

11 Jelicic M, van Boxtel MP, Houx PJ, Jolles J. Does migraine headache affect cognitive function in the elderly? Report from the Maastricht Aging Study (MAAS). Headache 2000;40:715-9.

12 Leijdekkers ML, Passchier J, Goudswaard P, Menges LJ, Orlebeke JF. Migraine patients cognitively impaired? Headache 1990;30:352-8.

13 Palmer JE, Chronicle EP. Cognitive processing in migraine: a failure to find facilitation in patients with aura. Cephalalgia 1998;18:125-32.
14 Pearson AJ, Chronicle EP, Maylor EA, Bruce LA. Cognitive function is not impaired in people with a long history of migraine: a blinded study. Cephalalgia 2006;26:74-80.

15 Calandre EP, Bembibre J, Arnedo ML, Becerra D. Cognitive disturbances and regional cerebral blood flow abnormalities in migraine patients: their relationship with the clinical manifestations of the illness. Cephalalgia 2002;22:291-302.

16 Hooker WD, Raskin NH. Neuropsychologic alterations in classic and common migraine. Arch Neurol 1986;43:709-12.

17 Le Pira F, Zappala G, Giuffrida S, Lo Bartolo ML, Reggio E, Morana R, et al. Memory disturbances in migraine with and without aura: a strategy problem? Cephalalgia 2000;20:475-8.

18 Mulder EJ, Linssen WH, Passchier J, Orlebeke JF, de Geus EJ. Interictal and postictal cognitive changes in migraine. Cephalalgia 1999;19:557-65; discussion 541.

19 Zeitlin C, Oddy M. Cognitive impairment in patients with severe migraine. Br J Clin Psychol 1984;23(Pt 1):27-35.

20 Baars MA, van Boxtel MP, Jolles J. Migraine does not affect cognitive decline: results from the Maastricht Aging Study. Headache 2010;50:176-84.

21 Kalaydjian A, Zandi PP, Swartz KL, Eaton WW, Lyketsos C. How migraines impact cognitive function: findings from the Baltimore ECA. Neurology 2007;68:1417-24.

22 Rist PM, Dufouil C, Glymour MM, Tzourio C, Kurth T. Migraine and cognitive decline in the population-based EVA study. Cephalalgia 2011;31:1291-300.

23 Lee IM, Cook NR, Gaziano JM, Gordon D, Ridker PM, Manson JE, et al. Vitamin E in the primary prevention of cardiovascular disease and cancer: the Women's Health Study: a randomized controlled trial. JAMA 2005;294:56-65.

24 Rexrode KM, Lee IM, Cook NR, Hennekens CH, Buring JE. Baseline characteristics of participants in the Women's Health Study. J Womens Health Gend Based Med 2000;9:19-27.

25 Ridker PM, Cook NR, Lee IM, Gordon D, Gaziano JM, Manson JE, et al. A randomized trial of low-dose aspirin in the primary prevention of cardiovascular disease in women. $N$ Engl J Med 2005;352:1293-304

26 Kang JH, Cook N, Manson J, Buring JE, Grodstein F. A randomized trial of vitamin E supplementation and cognitive function in women. Arch Intern Med 2006;166:2462-8.

27 Kang JH, Cook N, Manson J, Buring JE, Grodstein F. Low dose aspirin and cognitive function in the Women's Health Study cognitive cohort. BMJ 2007;334:987.

28 Kurth T, Gaziano JM, Cook NR, Logroscino G, Diener HC, Buring JE. Migraine and risk of cardiovascular disease in women. JAMA 2006;296:283-91.

29 Schurks M, Buring JE, Kurth T. Agreement of self-reported migraine with ICHD-II criteria in the Women's Health Study. Cephalalgia 2009;29:1086-90.

30 Folstein MF, Folstein SE, McHugh PR. "Mini-mental state." A practical method for grading the cognitive state of patients for the clinician. J Psychiatr Res 1975;12:189-98.

31 Brandt J, Spencer M, Folstein MF. The telephone interview for cognitive status. Neuropsychiatry Neuropsychol Behav Neurol 1988;1:111-7.

32 Albert M, Smith LA, Scherr PA, Taylor JO, Evans DA, Funkenstein HH. Use of brief cognitive tests to identify individuals in the community with clinically diagnosed Alzheimer's disease. Int J Neurosci 1991; 57:167-78.

33 Okereke OI, Kang JH, Cook NR, Gaziano JM, Manson JE, Buring JE, Grodstein F. Type 2 diabetes mellitus and cognitive decline in two large cohorts of community-dwelling older adults. J Am Geriatr Soc 2008;56:1028-36.

34 Weuve J, Ridker PM, Cook NR, Buring JE, Grodstein F. High-sensitivity C-reactive protein and cognitive function in older women. Epidemiology 2006:17:183-9.

35 De Jager CA, Budge MM, Clarke R. Utility of TICS-M for the assessment of cognitive function in older adults. Int J Geriatr Psychiatry 2003;18:318-24.

36 Lee S, Buring JE, Cook NR, Grodstein F. The relation of education and income to cognitive function among professional women. Neuroepidemiology 2006;26:93-101.

Accepted: 9 July 2012

\section{Cite this as: BMJ 2012;345:e5027}

This is an open-access article distributed under the terms of the Creative Commons Attribution Non-commercial License, which permits use, distribution, and reproduction in any medium, provided the original work is properly cited, the use is non commercial and is otherwise in compliance with the license. See: http://creativecommons.org/licenses/bync/2.0/ and http://creativecommons.org/licenses/by-nc/2.0/legalcode. 


\section{Tables} Table 1| Baseline characteristics of 6349 women according to migraine status. Values are numbers (percentages) of women unless stated
otherwise

\begin{tabular}{|c|c|c|c|c|}
\hline \multirow[b]{2}{*}{ Characteristic } & \multirow[b]{2}{*}{ No migraine history $(n=5496)$} & \multicolumn{2}{|c|}{ Migraine } & \multirow{2}{*}{$\begin{array}{l}\text { Past history of migraine } \\
\qquad(n=410)\end{array}$} \\
\hline & & With aura $(n=195)$ & Without aura $(n=248)$ & \\
\hline Mean (SD) age at study randomization (years) & $66.3(4.1)$ & $65.9(3.9)$ & $65.3(3.6)$ & $66.4(4.13)$ \\
\hline $\begin{array}{l}\text { Mean age (SD) at baseline cognitive interview } \\
\text { (years) }\end{array}$ & $71.9(4.1)$ & $71.6(3.9)$ & $71.0(3.5)$ & $72.1(4.1)$ \\
\hline \multicolumn{5}{|l|}{ Body mass index: } \\
\hline$<25$ & $2670(48.6)$ & $99(50.8)$ & $127(51.2)$ & $213(52.0)$ \\
\hline $25-29.9$ & $1860(33.8)$ & $70(35.9)$ & $83(33.5)$ & $136(33.2)$ \\
\hline$\geq 30$ & $833(15.2)$ & $21(10.8)$ & $34(13.7)$ & $54(13.2)$ \\
\hline History of hypertension & $2188(39.8)$ & $75(38.5)$ & $91(36.7)$ & $192(46.8)$ \\
\hline Antihypertensive drug use & $1230(22.4)$ & $40(20.5)$ & $56(22.6)$ & $100(24.4)$ \\
\hline History of high cholesterol levels & $2346(42.7)$ & $98(50.3)$ & $110(44.4)$ & $117(43.2)$ \\
\hline Cholesterol lowering drug use & $349(6.4)$ & $14(7.2)$ & $11(4.4)$ & $22(5.4)$ \\
\hline Oral contraceptive use & $1860(33.8)$ & 79 (40.5) & $84(33.9)$ & $160(39.0)$ \\
\hline \multicolumn{5}{|l|}{ Postmenopausal hormone use: } \\
\hline Never & $2258(41.1)$ & $48(24.6)$ & $84(33.9)$ & $143(34.9)$ \\
\hline Past & $1055(19.2)$ & $43(22.1)$ & $46(18.6)$ & $91(22.2)$ \\
\hline Current & $2175(39.6)$ & $104(53.3)$ & $118(47.6)$ & $174(42.4)$ \\
\hline \multicolumn{5}{|l|}{ Alcohol consumption: } \\
\hline Rarely/never & $2611(47.5)$ & $98(50.3)$ & $122(49.2)$ & $193(47.1)$ \\
\hline 1-3 drinks/month & $626(11.4)$ & $25(12.8)$ & $34(13.7)$ & $55(13.4)$ \\
\hline 1-6 drinks/week & $1569(28.6)$ & $50(25.6)$ & $76(30.7)$ & $110(26.8)$ \\
\hline$\geq 1$ drinks per day & $686(12.5)$ & $22(11.3)$ & $16(6.5)$ & $52(12.7)$ \\
\hline \multicolumn{5}{|l|}{ Vigorous physical activity: } \\
\hline Rarely/never & $2369(43.1)$ & $81(41.5)$ & $120(48.4)$ & $164(40.0)$ \\
\hline$<1 /$ week & $887(16.1)$ & $37(19.0)$ & $43(17.3)$ & $72(17.6)$ \\
\hline 1-3 times/week & $1575(28.7)$ & $54(27.7)$ & $60(24.2)$ & $125(30.5)$ \\
\hline$\geq 4$ times/week & $662(12.1)$ & $23(11.8)$ & $24(9.7)$ & $48(11.7)$ \\
\hline \multicolumn{5}{|l|}{ Smoking status: } \\
\hline Never & $2863(52.1)$ & $102(52.3)$ & $141(56.9)$ & $219(53.4)$ \\
\hline Former & $2072(37.7)$ & $74(38.0)$ & $88(35.5)$ & $153(37.3)$ \\
\hline Current & $556(10.1)$ & $19(9.7)$ & $18(7.3)$ & $38(9.3)$ \\
\hline Diabetes & $202(3.7)$ & $3(1.5)$ & $5(2.0)$ & $10(2.4)$ \\
\hline \multicolumn{5}{|l|}{ Highest attained education: } \\
\hline LPVN, associates degree, registered nurse & $3598(65.5)$ & $130(66.7)$ & $173(69.8)$ & $295(72.0)$ \\
\hline Bachelor's degree or higher education & $1810(32.9)$ & $65(33.3)$ & $70(28.2)$ & $114(27.8)$ \\
\hline $\begin{array}{l}\text { Mean (SD) baseline telephone interview for } \\
\text { cognitive status score }\end{array}$ & $34.2(2.7)$ & $34.3(2.6)$ & $34.4(2.5)$ & $34.4(2.6)$ \\
\hline Mean (SD) baseline immediate EBMT & $9.6(1.6)$ & $9.6(1.6)$ & $9.6(1.5)$ & $9.7(1.7)$ \\
\hline Mean (SD) baseline delayed EBMT & $9.3(1.8)$ & $9.4(1.7)$ & $9.3(1.6)$ & $9.4(1.7)$ \\
\hline Mean (SD) baseline immediate 10 word list recall & $4.8(1.8)$ & $4.9(1.8)$ & $4.9(1.8)$ & $5.0(1.7)$ \\
\hline Mean (SD) baseline delayed 10 word list recall & $3.0(2.1)$ & $2.9(1.9)$ & $3.0(2.1)$ & $3.1(2.0)$ \\
\hline Mean (SD) baseline category fluency score & $17.5(4.9)$ & $18.2(5.1)$ & $18.0(5.0)$ & $17.8(5.0)$ \\
\hline
\end{tabular}

LPVN=licensed practical nurse/licensed vocational nurse; EBMT=east Boston memory test.

Numbers may not add up to $100 \%$ because of rounding or missing data. 
Table 2| Multivariable adjusted mean cognitive scores and standard errors at each follow-up assessment (about two years apart) by migraine status

\begin{tabular}{|c|c|c|c|c|c|c|c|c|c|}
\hline \multirow{2}{*}{$\begin{array}{l}\text { Cognitive } \\
\text { tests at } \\
\text { assessment } \\
\text { points }\end{array}$} & \multicolumn{2}{|c|}{ No history of migraine } & \multicolumn{2}{|c|}{ Migraine with aura } & \multicolumn{2}{|c|}{ Migraine without aura } & \multicolumn{2}{|c|}{ Past history of migraine } & \multirow[b]{2}{*}{$\begin{array}{l}\text { Overall } \\
\text { P value }\end{array}$} \\
\hline & $\begin{array}{c}\text { No of } \\
\text { participants }\end{array}$ & $\begin{array}{c}\text { Adjusted } \\
\text { mean }^{*}(S E)\end{array}$ & $\begin{array}{c}\text { No of } \\
\text { participants }\end{array}$ & $\begin{array}{c}\text { Adjusted } \\
\text { mean }^{*}(\mathrm{SE})\end{array}$ & $\begin{array}{c}\text { No of } \\
\text { participants }\end{array}$ & $\begin{array}{c}\text { Adjusted } \\
\text { mean* }^{*}(\mathrm{SE})\end{array}$ & $\begin{array}{c}\text { No of } \\
\text { participants }\end{array}$ & $\begin{array}{c}\text { Adjusted } \\
\text { mean* }^{*}(\mathrm{SE})\end{array}$ & \\
\hline \multicolumn{10}{|l|}{ Global scoret: } \\
\hline First & 5496 & $-0.02(0.03)$ & 195 & $0.01(0.05)$ & 248 & $-0.01(0.05)$ & 410 & $0.05(0.04)$ & 0.11 \\
\hline Second & 4902 & $0.05(0.04)$ & 174 & $0.08(0.06)$ & 220 & $0.07(0.06)$ & 370 & $0.12(0.05)$ & 0.30 \\
\hline Third & 4496 & $-0.02(0.04)$ & 167 & $0.08(0.07)$ & 202 & $0.04(0.06)$ & 337 & $0.03(0.05)$ & 0.15 \\
\hline \multicolumn{10}{|l|}{ Verbal scoret: } \\
\hline First & 5496 & $-0.03(0.03)$ & 195 & $-0.02(0.06)$ & 248 & $-0.03(0.05)$ & 410 & $0.05(0.05)$ & 0.18 \\
\hline Second & 4902 & $0.12(0.04)$ & 174 & $0.17(0.07)$ & 220 & $0.14(0.06)$ & 370 & $0.16(0.05)$ & 0.69 \\
\hline Third & 4496 & $0.08(0.04)$ & 167 & $0.17(0.07)$ & 202 & $0.12(0.07)$ & 337 & $0.13(0.06)$ & 0.31 \\
\hline \multicolumn{10}{|l|}{$\begin{array}{l}\text { Telephone } \\
\text { interview for } \\
\text { cognitive } \\
\text { status: }\end{array}$} \\
\hline First & 5483 & $34.18(0.13)$ & 195 & $34.24(0.23)$ & 248 & $34.29(0.21)$ & 408 & $34.48(0.18)$ & 0.17 \\
\hline Second & 4898 & $33.85(0.14)$ & 174 & $33.80(0.25)$ & 220 & $33.95(0.24)$ & 370 & $33.88(0.20)$ & 0.94 \\
\hline Third & 4496 & $33.88(0.16)$ & 167 & $33.86(0.27)$ & 202 & $34.02(0.26)$ & 337 & $33.99(0.22)$ & 0.84 \\
\hline \multicolumn{10}{|l|}{$\begin{array}{l}\text { Category } \\
\text { fluency test: }\end{array}$} \\
\hline First & 5476 & $17.22(0.24)$ & 195 & $17.86(0.42)$ & 247 & $17.58(0.39)$ & 407 & $17.63(0.33)$ & 0.09 \\
\hline Second & 4898 & $17.52(0.27)$ & 174 & $17.51(0.47)$ & 220 & $17.72(0.44)$ & 370 & $18.43(0.37)$ & 0.01 \\
\hline Third & 4495 & $16.82(0.28)$ & 167 & $17.94(0.48)$ & 202 & $17.46(0.45)$ & 337 & $17.05(0.39)$ & 0.01 \\
\hline
\end{tabular}

$P$ values from analysis of covariance comparing no history of migraine, migraine with aura, migraine without aura, and past history of migraine.

*Adjusted for age, smoking status, alcohol consumption, body mass index, educational attainment, postmenopausal hormone use, history of high cholesterol levels, treatment for high cholesterol levels, history of hypertension, treatment for hypertension, diabetes, and past oral contraceptive use.

†Scores measured in standardised units. 


\begin{tabular}{|c|c|c|c|c|c|c|c|c|}
\hline \multirow[b]{2}{*}{$\begin{array}{l}\text { Migraine status and } \\
\text { assessments }\end{array}$} & \multicolumn{2}{|c|}{ Global score* } & \multicolumn{2}{|c|}{ Verbal score* } & \multicolumn{2}{|c|}{$\begin{array}{l}\text { Telephone interview for } \\
\text { cognitive status }\end{array}$} & \multicolumn{2}{|c|}{ Category fluency score } \\
\hline & $\begin{array}{l}\text { Coefficient } \\
\text { (SE) }\end{array}$ & $P$ value & $\begin{array}{l}\text { Coefficient } \\
\text { (SE) }\end{array}$ & $P$ value & Coefficient (SE) & $P$ value & $\begin{array}{l}\text { Coefficient } \\
\text { (SE) }\end{array}$ & $P$ value \\
\hline \multicolumn{9}{|l|}{ Age adjusted } \\
\hline $\begin{array}{l}\begin{array}{l}\text { First assessment } \\
\text { (reference) }\end{array} \\
\end{array}$ & - & - & - & - & - & - & - & - \\
\hline Second assessment & $0.07(0.01)$ & $<0.01$ & $0.13(0.01)$ & $<0.01$ & $-0.11(0.04)$ & 0.01 & $0.54(0.07)$ & $<0.01$ \\
\hline Third assessment & $0.02(0.01)$ & 0.06 & $0.10(0.01)$ & $<0.01$ & $-0.12(0.04)$ & 0.01 & $0.03(0.07)$ & 0.70 \\
\hline $\begin{array}{l}\text { No migraine } \\
\text { (reference) }\end{array}$ & - & - & - & - & - & - & - & - \\
\hline Migraine with aura: & $0.03(0.04)$ & 0.47 & $0.01(0.05)$ & 0.83 & $0.05(0.19)$ & 0.80 & $0.65(0.36)$ & 0.07 \\
\hline Second assessment & $-0.02(0.05)$ & 0.68 & $0.02(0.05)$ & 0.72 & $-0.12(0.21)$ & 0.58 & $-0.77(0.39)$ & 0.05 \\
\hline Third assessment & $0.05(0.05)$ & 0.29 & $0.06(0.06)$ & 0.28 & $-0.11(0.22)$ & 0.61 & $0.36(0.40)$ & 0.37 \\
\hline Migraine without aura: & $0.0045(0.04)$ & 0.90 & $-0.02(0.04)$ & 0.67 & $0.05(0.16)$ & 0.75 & $0.34(0.32)$ & 0.28 \\
\hline Second assessment & $0.03(0.04)$ & 0.48 & $0.05(0.05)$ & 0.36 & $0.09(0.19)$ & 0.64 & $-0.12(0.33)$ & 0.71 \\
\hline Third assessment & $0.08(0.04)$ & 0.09 & $0.08(0.05)$ & 0.15 & $0.26(0.20)$ & 0.19 & $0.28(0.34)$ & 0.41 \\
\hline $\begin{array}{l}\text { Past history of } \\
\text { migraine: }\end{array}$ & $0.07(0.03)$ & 0.03 & $0.07(0.03)$ & 0.047 & $0.24(0.13)$ & 0.06 & $0.35(0.25)$ & 0.16 \\
\hline Second assessment & $-0.0047(0.03)$ & 0.89 & $-0.03(0.04)$ & 0.46 & $-0.24(0.16)$ & 0.13 & $0.44(0.29)$ & 0.13 \\
\hline Third assessment & $-0.01(0.04)$ & 0.74 & $-0.01(0.04)$ & 0.72 & $-0.13(0.16)$ & 0.42 & $-0.09(0.27)$ & 0.74 \\
\hline \multicolumn{9}{|c|}{ Multivariable adjusted $\dagger$} \\
\hline $\begin{array}{l}\text { First assessment } \\
\text { (reference) }\end{array}$ & - & - & - & - & - & - & - & - \\
\hline Second assessment & $0.07(0.01)$ & $<0.01$ & $0.13(0.01)$ & $<0.01$ & $-0.11(0.04)$ & 0.01 & $0.54(0.07)$ & $<0.01$ \\
\hline Third assessment & $0.02(0.01)$ & 0.07 & $0.09(0.01)$ & $<0.01$ & $-0.12(0.04)$ & 0.01 & $0.02(0.07)$ & 0.77 \\
\hline $\begin{array}{l}\text { No migraine } \\
\text { (reference) }\end{array}$ & - & - & - & - & - & - & - & - \\
\hline Migraine with aura: & $0.03(0.04)$ & 0.49 & $0.01(0.05)$ & 0.85 & $0.04(0.18)$ & 0.83 & $0.65(0.36)$ & 0.07 \\
\hline Second assessment & $-0.02(0.05)$ & 0.69 & $0.02(0.05)$ & 0.71 & $-0.11(0.21)$ & 0.59 & $-0.77(0.39)$ & 0.05 \\
\hline Third assessment & $0.05(0.05)$ & 0.28 & $0.06(0.06)$ & 0.28 & $-0.11(0.22)$ & 0.62 & $0.37(0.40)$ & 0.36 \\
\hline Migraine without aura: & $0.01(0.04)$ & 0.75 & $-0.01(0.04)$ & 0.77 & $0.07(0.16)$ & 0.65 & $0.36(0.31)$ & 0.24 \\
\hline Second assessment & $0.03(0.04)$ & 0.48 & $0.05(0.05)$ & 0.35 & $0.09(0.19)$ & 0.64 & $-0.12(0.33)$ & 0.72 \\
\hline Third assessment & $0.08(0.04)$ & 0.09 & $0.08(0.05)$ & 0.15 & $0.25(0.20)$ & 0.21 & $0.28(0.34)$ & 0.41 \\
\hline $\begin{array}{l}\text { Past history of } \\
\text { migraine: }\end{array}$ & $0.08(0.03)$ & 0.01 & $0.08(0.03)$ & 0.03 & $0.29(0.13)$ & 0.02 & $0.42(0.25)$ & 0.09 \\
\hline Second assessment & $-0.0047(0.03)$ & 0.89 & $-0.03(0.04)$ & 0.46 & $-0.24(0.16)$ & 0.13 & $0.44(0.29)$ & 0.13 \\
\hline Third assessment & $-0.01(0.04)$ & 0.75 & $-0.01(0.04)$ & 0.72 & $-0.13(0.16)$ & 0.43 & $-0.09(0.27)$ & 0.75 \\
\hline
\end{tabular}

Global score and category fluency do not control for treatment for high cholesterol levels owing to problems with model convergence. The coefficients shown are the results of the joint effects of migraine status and the respective follow-up time.

*Measured in standardised units.

†Adjusted for age, smoking status, alcohol consumption, body mass index, educational attainment, postmenopausal hormone use, history of high cholesterol levels, treatment for high cholesterol levels, history of hypertension, treatment for hypertension, diabetes, and past oral contraceptive use. 


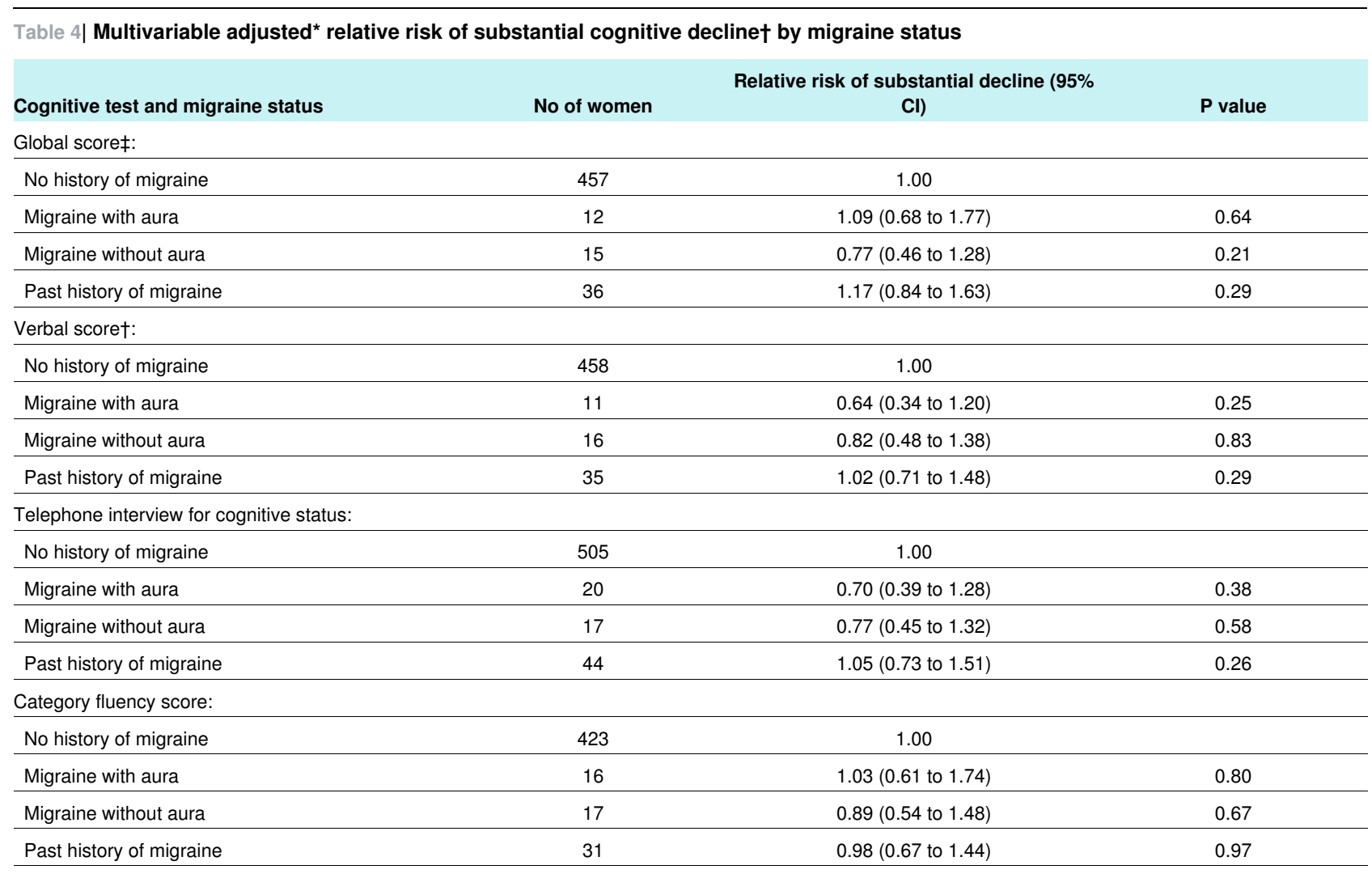

*Adjusted for age, smoking status, alcohol consumption, body mass index, educational attainment, postmenopausal hormone use, history of high cholesterol levels, treatment for high cholesterol levels, history of hypertension, treatment for hypertension, diabetes, past oral contraceptive use, and time from entry into the Women's Health Study to last interview.

†Substantial cognitive decline was defined as the worst $10 \%$ of the distribution of decline from the initial to the final cognitive assessment of the whole study cohort. ¥Measured in standardised units. 


\section{Figure}

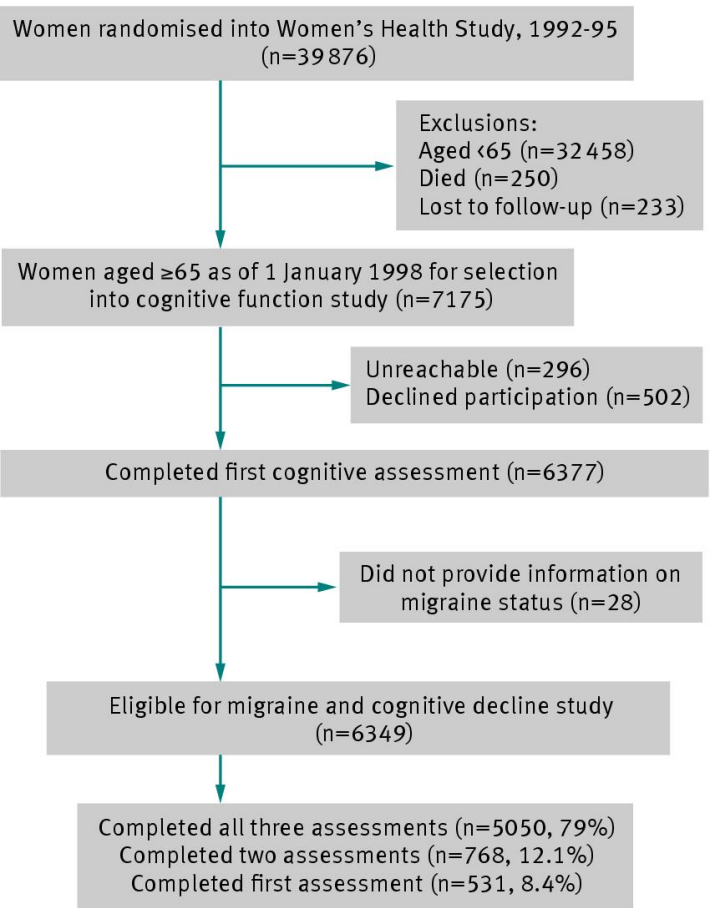

Flow chart of participation in migraine and cognitive decline study among women enrolled in the Women's Health Study 